\title{
The Importance of Prolactin Levels in Patients Treated with Cabergoline for the Prevention of OHSS: Is Cabergoline Really Effective in Patients with High Risk of OHSS?
}

\author{
Serkan Oral ${ }^{*}$, Yaşam Kemal Akpak², Nilay Karaca3, Kadir Savan ${ }^{4}$ \\ ${ }^{1}$ Department of Assisted Reproduction, LIV Hospital, Istanbul, Turkey \\ ${ }^{2}$ Department of Obstetrics and Gynecology, Ankara Mevki Military Hospital, Ankara, Turkey \\ ${ }^{3}$ Department of Obstetrics and Gynecology, Bezmi Alem Vakif University Hospital, Istanbul, Turkey \\ ${ }^{4}$ Department of Assisted Reproduction, Bahcelievler Medicalpark Hospital, Istanbul, Turkey \\ Email: ${ }^{*}$ drserkanoral@gmail.com
}

Received 24 May 2015; accepted 20 June 2015; published 23 June 2015

Copyright (C) 2015 by authors and Scientific Research Publishing Inc.

This work is licensed under the Creative Commons Attribution-NonCommercial International License (CC BY-NC).

http://creativecommons.org/licenses/by-nc/4.0/

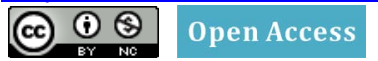

\section{Abstract}

Background: OHSS is a dangerous and potentially life-threatening condition for which many researchers look for new ways to treat. Aim: To determine the effectiveness of prophylactic cabergoline administration on prolactine levels in patients with high risk for ovarian hyperstimulation syndrome (OHSS). Material and Methods: 163 in vitro fertilisation (IVF) patients with high risk for OHSS were enrolled in the study. The criteria for inclusion were more than 15 oocytes retrieved at oocyte pick up. A standard antagonist protocol was used for ovulation induction. Cabergoline treatments $(0.5 \mathrm{mg} / \mathrm{day})$ were started on the day of oocyte retrieval and continued for eight days. Prolactine levels were measured at the day of oocyte retrieval and the 9 th day after the oocyte retrieval. Results: Of the 163 patients, $26(15.9 \%)$ had OHSS. Prolactine levels on the day of oocyte retrieval were $44.22 \pm 24.78 \mathrm{ng} / \mathrm{mL}$ and $37.6 \pm 22.5 \mathrm{ng} / \mathrm{mL}$ in patients with $\mathrm{OHSS}$ and without OHSS, respectively $(P>0.05)$. In contrary prolactine levels were significantly higher in patients with OHSS patients $(3.9 \pm 5.07 \mathrm{ng} / \mathrm{mL})$ than in patients without $0 H S S(2.1 \pm 2.92 \mathrm{ng} / \mathrm{mL})$ at the 9 th day after oocyte retrieval $(P<0.05)$. Conclusion: Prolactine levels were higher in patients with OHSS than without OHSS who were treated with cabergoline for the prevention of OHSS.

\section{Keywords}

Cabergoline, Ovarian Hyperstimulation Syndrome (OHSS), Prolactine Levels, In Vitro Fertilization

*Corresponding author. 


\section{Introduction}

In the modern world, most of the couples marry in advanced ages due to concern for the future, have babies in advanced ages. This situation increases the application of assisted reproduction techniques [1]. The ovarian hyperstimulation syndrome (OHSS) is an iatrogenic complication of ovarian stimulation treatments for ovulation induction and in vitro fertilization with the incidence of severe forms, $0.1 \%$ - 5\% [2]. OHSS is a dangerous and potentially life-threatening condition which many researchers look for new ways to treat this medical dilemma. The clinical situation varies from abdominal distension and discomfort to a potentially life threatening disease with massive ovarian enlargement and third space fluid effusion [3]. The pathophysiology of the syndrome has not been completely elucidated yet.

OHSS is a self-limiting disorder with an extensive spectrum of clinical processes related to increased capillary permeability of mesothelial surfaces under the action of one or several vasoactive ovarian factors [3]. The clinical characteristics of the syndrome stem from an intense inflammatory reaction that results in massive accumulation of extracellular protein rich fluid, which manifests as massive ascites and pleural and pericardial effusion, combined with profound intravascular volume depletion and hemoconcentration about by many biochemical mediators [4]. Also human chorionic gonadotropin (hCG) is thought to play a crucial role in the development of the syndrome, because severe forms are indeed restricted to cycles with exogenous hCG (to induce ovulation or as luteal phase support) or with endogenous pregnancy-derived hCG [5]. The angiogenic molecule vascular endothelial growth factor (VEGF) is the most important mediator of hCG-dependent ovarian angiogenesis. Its expression is increased by the hCG molecule. It is known that VEGF is expressed in human ovaries and that VEGF mRNA levels increase after hCG administration in granulosa cells [6], whereas elevated levels of secreted proteins are detected in serum, plasma, and peritoneal fluids in women at risk or with OHSS [7]. Therefore, attention has been focused on the expression of VEGF and its receptors during the ovarian stimulation process, on how hCG affects its expression and on the association between such changes and the exacerbation of the clinical symptoms of OHSS. If OHSS is envisioned, there are some methods to decrease the risk of developing OHSS such as coasting, cryopreservation of all embryos, cycle cancellation, follicle-stimulating hormone (FSH) with low-dose hCG, replacing hCG with a gonadotropin releasing hormone (GnRH) agonist to induce final follicular maturation, albumin, and cabergoline (Cb2) [8]. It has been demonstrated that in animals and in human; the dopamine receptor 2 agonist cabergoline inactivates VEGF receptor-2 (VEGFR2) and prevents increased vascular permeability [9].

The aim of this study is to define the effect of prophylactic cabergoline administration on prolactin levels in patients with high risk of OHSS.

\section{Material and Methods}

\subsection{Patients}

The study was approved by the Zeynep Kamil Women and Children Diseases Education and Research Hospital Ethics Committee with the approval number 102, and informed consent was obtained from all the participants. Our study was designed at Assisted Reproductive Center of Medical Park Bahcelievler Hospital after getting permission from Instutional Review Board between January 2007 and December 2009. A total of 163 IVF patients with high risk of OHSS were enrolled in the study. The inclusion criteria was more than 15 oocytes which were obtained at oocyte pick up. We used standard antagonist protocol for ovulation induction. The recombinant FSH (Gonal-f; Merck Serono, Turkey) was given according to ovarian reserve tests (basal FSH, antral follicle count). The antagonist (Cetrotide; Merck Serono, Turkey) was started at a dose of 0.25 mg/day when the leading follicle reached a diameter of $11 \mathrm{~mm}$ or larger. Recombinant hCG $250 \mu \mathrm{g}$ (Ovitrelle; Merck Serono, Turkey) was given when a minimum of three follicles have reached $17 \mathrm{~mm}$ diameter. The oocytes were picked up 36 hours after the administration of hCG by transvaginal ultrasound and the embryo transfer was done at cleavage stage (day 2 or day 3). Intravaginal progesterone gel was given (Crinone 8\%, Merck Serono, Turkey) for luteal phase support. Serum prolactin level was measured at the day of oocyte retrieval and cabergoline (Dostinex, 
Pfizer, Turkey) $0.5 \mathrm{mg} /$ day was administered for eight days after the day of oocyte retrieval. Prolactin level was reevaluated, one day later, after stopping the administration of cabergoline. The signs and the symptoms of OHSS were explained to all patients and the ultrasonographic monitorization was done seven days after the embryo transfer for ovarian enlargement and presence of ascites. The classification of Golan et al. [10] was used for diagnosis of OHSS. Severe OHSS was diagnosed in patients that established clinical evidence of ascites and/or hydrothorax and breathing difficulties or one of the following criteria: 1) Hemoglobin at least $15 \mathrm{~g} / \mathrm{dl}$ or hematocrit at least $45 \%$, or leukocyte count at least $20.000 / \mathrm{mm}^{3}$; 2) Coagulation abnormality; 3) Serum creatinine levels $<1.2 \mathrm{mg} / \mathrm{dl}$; 4) Aspartate aminotransferase (AST) or alanine aminotransferase (ALT) $>40 \mathrm{U} / \mathrm{ml}$. However, the diagnosis of moderate OHSS required only ultrasonographic evidence of ascites.

\subsection{Statistical Analysis}

Data were assessed in SPSS v.15.0 for statistical analysis and Mann Witney U test was used for the univariate data. Results were referred as means \pm standart deviation. The statistical significance was accepted as $\mathrm{P}$ value of $<0.05$.

\section{Results}

Totally 26 patients (15.9\%) had signs of OHSS. These patients were classified as stage I (7 patients), stage II (8 patients) and stage III (11 patients). Age, basal FSH, body mass index (BMI), total dose of gonodotrophine, serum estradiol (E2) levels on the day of hCG, the number of oocytes retrieved, the number of embryos transferred and the pregnancy rates were not significantly different in patients with or without OHSS. The difference between prolactin levels on the day of retrieval was also not significant; although the prolactin levels were significantly higher in OHSS patients at the $9^{\text {th }}$ day after oocyte retrieval, following cabergoline administration (Table 1).

\section{Discussion}

The use of IVF is increasing and its complications are also becoming more common. OHSS is a clinical manifestation characterized by ovarian enlargement, acute fluid shift from the intravascular space to the third space, risk of thromboembolism, abdominal distention, breathing difficulties and consequently a potentially life-threatening condition [2]. The pathophysiology of OHSS is not yet completely elucidated but VEGF and VEGFR, which are found in the granulosa cells of the corpus luteum, play a pivotal role in the development of OHSS. Also hCG and gonadotropins increase the amount of VEGF. These factors and receptors are responsible from endotel remodelling and acute fluid shift [8]. Therefore, VEGFRs automatically become a target for studies of treatment. Because of variable side effects, anti-angiogenic drugs on vascular permeability cannot be used in the treatment of OHSS. Recent studies were carried out, which have proven that dopamine agonists can inhibit phosphorylation of the receptor VEGFR-2 and prevent the increase in vascular permeability. In recent research findings in animal models of OHSS, dopamine agonists have been shown to be effective [9]-[11]. Cb2 is the most commonly

Table 1. Comparison of clinical, hormonal and cycle characteristics of patients with and without OHSS.

\begin{tabular}{cccc}
\hline & Patients without OHSS & Patients with OHSS & P values \\
\hline Age & $28.51 \pm 4.67$ & $28.35 \pm 4.04$ & 0.708 \\
FSH 3rd day & $6.31 \pm 1.77$ & $6.62 \pm 2.03$ & 0.482 \\
BMI & $27.26 \pm 5.43$ & $25.54 \pm 4.79$ & 0.118 \\
Total dose of gonodotrophines/day & $254.17 \pm 68.37$ & $238.46 \pm 50.12$ & 0.341 \\
E2 at day of HCG & $3207.11 \pm 1543.07$ & $3122.85 \pm 1251.61$ & 0.873 \\
Oocytes retrieved & $20.56 \pm 5.96$ & $22.15 \pm 5.78$ & 0.131 \\
Number of embryos transferred & $2.67 \pm 0.65$ & $2.69 \pm 0.55$ & 0.782 \\
Pregnancy rate & $0.39 \pm 0.37$ & $0.51 \pm 0.29$ & 0.065 \\
Prolactine ng/mL day 0 & $37.60 \pm 22.50$ & $44.22 \pm 24.78$ & 0.186 \\
Prolactine ng/mL 9th day & $2.10 \pm 2.92$ & $3.90 \pm 5.07$ & $\mathbf{0 . 0 2 3 ^ { * }}$
\end{tabular}


used dopamine agonist for OHSS prevention [12]. Cb2 has been examined with a decrease in the severity and incidence of OHSS [13]-[16]. Randomized controlled trials, which are more important for us, have indicated that the same results were verified. Also Cb2 was found cost-effective compared with the albumin [17]. Our results have proven that patients who received $\mathrm{Cb} 2$ demonstrated significant difference in the severity and also incidence of OHSS presentation. Our results emphasized that the use of Cb2 in the oocyte retrieval day reduced the severity and incidence of OHSS significantly. In a review, according to the number needed to treat, for every 100 people at risk of OHSS when treated with cabergoline 14 cases of OHSS, including one severe and 13 moderate cases, would be avoided [11]. In our study this data has been found exponentially more. $0.25 \mathrm{mg}$ or $0.5 \mathrm{mg}$ dose of $\mathrm{Cb} 2$, which is found from treatment of prolactinomas, reduce the development of OHSS [18]. However, there is very important information which should be underlined in our study. 9th day prolactin levels of patients with OHSS were statistically significantly higher than patients without OHSS. Of course there is no doubt that those patients who developed OHSS had higher prolactin levels, since prolactin is a stress hormone and higher levels of prolactin are known to be associated with OHSS. However this vicious cycle is related to the mechanism of OHSS.

The information set out earlier in a case report became clearer in our study. Though shown in a case report higher doses and long-term use (such as $1 \mathrm{mg}$ and 14 days) could treat severe OHSS case [19], our result showed that more patients may be treated in decent dose and duration. Further studies can be designed to evaluate the more effective dose and duration time of $\mathrm{Cb} 2$ administration. There is a controversy about time to start the treatment of $\mathrm{Cb} 2$. The result of $\mathrm{Cb} 2$ administration such as final oocyte maturation and fertilization rate, or subsequent clinical outcome, either in the day of hCG injection or in the oocyte retrieval day is still unknown [20]. Implantation rates were not affected by Cb2 [21]-[23], in a review indicating no significant difference between the groups in regard to pregnancy outcomes such as miscarriage and clinical pregnancy rate [18]. Also OHSS development did not affect pregnancy rates in our study. If we examine for side effects of Cb2, in the literature an increased incidence of cardiac valvulopathy may be monitored. However, this diagnosis might be through the longer duration and higher dose of Cb2 treatment like Parkinson's disease [12] [18]. There was not such finding in any of our patients. We recognize the important limitation of our retrospective study. There is no comparison group that did not receive cabergoline. Although OHSS has been predicted, we supposed that not to interfere with these patients is unethical.

\section{Conclusion}

In conclusion, as OHSS has not a definite etiology, its treatment still remains great problem but Cb2 seems to reduce the incidence of moderate or severe OHSS in high-risk IVF patients. Unfortunately, we need data to evaluate the long-term safety of Cb2.

\section{Consent}

Written informed consent was obtained from all participants. Written consent was obtained from the local Ethics Committee.

\section{Conflict of Interest}

The authors declare that they have no conflict of interest. We certify that we had no relationship with companies that may have a financial interest.

\section{References}

[1] Temel, T., Akpak, Y.K., Gün, İ., Oral, S. and Sofuoğlu, K. (2015) Impact of Paternal Age on Intracytoplasmic Sperm Injection Cycle Results. International Journal of Reproduction, Contraception, Obstetrics and Gynecology, 4, 622628. http://dx.doi.org/10.18203/2320-1770.ijrcog20150063

[2] Mathur, R., Kailasam, C.H. and Jenkins, J. (2007) Review of the Evidence Base of Strategies to Prevent Ovarian Hyper Stimulation Syndrome. Human Fertility, 10, 75-85. http://dx.doi.org/10.1080/14647270601111239

[3] Aboulghar, M.A. and Mansour, R.T. (2003) Ovarian Hyperstimulation Syndrome: Classifications and Critical Analysis of Preventive Measures. Human Reproduction Update, 9, 275-289. http://dx.doi.org/10.1093/humupd/dmg018

[4] Fiedler, K. and Ezcurra, D. (2012) Predicting and Preventing Ovarian Hyperstimulation Syndrome (OHSS): The Need 
for Individualized Not Standardized Treatment. Reproductive Biology and Endocrinology, 10, 32. http://dx.doi.org/10.1186/1477-7827-10-32

[5] Saylan, A., Arioz, D.T., Koken, T., Dilek, H., Saylan, F. and Yilmazer, M. (2010) Prevention of Ovarian Hyperstimulation Syndrome in a Rat Model: Efficacy Comparison between Cabergoline and Meloxicam. Acta Obstetricia et Gynecologica Scandinavica, 89, 692-699. http://dx.doi.org/10.3109/00016341003592537

[6] Wang, T.H., Horng, S.G., Chang, C.L., Wu, H.M., Tsai, Y.J., Wang, H.S. and Soong, Y.K. (2002) Human Chorionic Gonadotropin-Induced Ovarian Hyperstimulation Syndrome Is Associated with Up-Regulation of Vascular Endothelial Growth Factor. Journal of Clinical Endocrinology Metabolism, 87, 3300-3308. http://dx.doi.org/10.1210/jcem.87.7.8651

[7] Pellicer, A., Albert, C., Mercader, A., Bonilla-Musoles, F., Remohí, J. and Simón, C. (1999) The Pathogenesis of Ovarian Hyperstimulation Syndrome: In Vivo Studies Investigating the Role of Interleukin-1beta, Interleukin-6, and Vascular Endothelial Growth Factor. Fertility and Sterility, 71, 482-489. http://dx.doi.org/10.1016/S0015-0282(98)00484-1

[8] Leitao, V.M., Moroni, R.M., Seko, L.M., Nastri, C.O. and Martins, W.P. (2014) Cabergoline for the Prevention of Ovarian Hyperstimulation Syndrome: Systematic Review and Meta-Analysis of Randomized Controlled Trials. Fertility and Sterility, 101, 664-675. http://dx.doi.org/10.1016/j.fertnstert.2013.11.005

[9] Gomez, R., Gonzalez-Izquierdo, M., Zimmermann, R.C., Novella-Maestre, E., Alonso-Muriel, I., Sanchez-Criado, J., Remohi, J., Simon, C. and Pellicer, A. (2006) Low-Dose Dopamine Agonist Administration Blocks Vascular Endothelial Growth Factor (VEGF)-Mediated Vascularhyperpermeability without Altering VEGF Receptor 2-Dependent Luteal Angiogenesis in a Rat Ovarianhyperstimulation Model. Endocrinology, 147, 5400-5411. http://dx.doi.org/10.1210/en.2006-0657

[10] Golan, A., Ronel, R., Herman, A., Soffer, Y., Weinraub, Z. and Caspi, E. (1989) Ovarian Hyperstimulation Syndrome: An Update Review. Obstetrical Gynecological Survey, 44, 430-440. http://dx.doi.org/10.1097/00006254-198906000-00004

[11] Tang, H., Hunter, T., Hu, Y., Zhai, S.D., Sheng, X. and Hart, R.J. (2012) Cabergoline for Preventing Ovarian Hyperstimulation Syndrome. Cochrane Database of Systematic Reviews, 2, CD008605. http://dx.doi.org/10.1002/14651858.cd008605.pub2

[12] Kalampokas, T., Creatsas, G. and Kalampokas, E. (2013) Cabergoline as Treatment of Ovarian Hyperstimulation Syndrome: A Review. Gynecological Endocrinology, 29, 98-100. http://dx.doi.org/10.3109/09513590.2012.730578

[13] Alvarez, C., Alonso-Muriel, I., García, G., Crespo, J., Bellver, J., Simón, C. and Pellicer, A. (2007) Implantation is Apparently Unaffected by the Dopamine Agonist Cabergoline When Administered to Prevent Ovarian Hyperstimulation Syndrome in Women Undergoing Assisted Reproduction Treatment: A Pilot Study. Human Reproduction, 22, 3210-3214. http://dx.doi.org/10.1093/humrep/dem315

[14] Carizza, C., Abdelmassih, V., Abdelmassih, S., Ravizzini, P., Salgueiro, L., Salgueiro, P.T., Jine, L.T., Nagy, P. and Abdelmassih, R. (2008) Cabergoline Reduces the Early Onset of Ovarian Hyperstimulation Syndrome: A Prospective Randomized Study. Reproductive BioMedicine Online, 17, 751-755. http://dx.doi.org/10.1016/S1472-6483(10)60401-4

[15] Sohrabvand, F., Ansaripour, S., Bagheri, M., Shariat, M. and Jafarabadi, M. (2009) Cabergoline versus Coasting in the Prevention of Ovarian Hyperstimulation Syndrome and Assisted Reproductive Technologies Outcome in High Risk Patients. International Journal of Fertility and Sterility, 3, 35-40.

[16] Hwang, J.L., Lin, Y.H. and Soew, K.M. (2010) Failure of Cabergoline to Prevent Severe Ovarian Hyperstimulation Syndrome in Patients with Extremely High Estradiol Levels. International Journal of Gynecology \& Obstetrics, 108, 159-160. http://dx.doi.org/10.1016/j.ijgo.2009.09.017

[17] Tehraninejad, E.S., Hafezi, M., Arabipoor, A., Aziminekoo, E., Chehrazi, M. and Bahmanabadi, A. (2012) Comparison of Cabergoline and Intravenous Albumin in the Prevention of Ovarian Hyperstimulation Syndrome: A Randomized Clinical Trial. Journal of Assisted Reproduction and Genetics, 29, 259-264. http://dx.doi.org/10.1007/s10815-011-9708-4

[18] Youssef, M.A., van Wely, M., Hassan, M.A., Al-Inany, H.G., Mochtar, M., Khattab, S. and van der Veen, F. (2010) Can Dopamine Agonists Reduce the Incidence and Severity of OHSS in IVF/ICSI Treatment Cycles? A Systematic Review and Meta-Analysis. Human Reproduction Update, 16, 459-466. http://dx.doi.org/10.1093/humupd/dmq006

[19] Ata, B., Seyhan, A., Orhaner, S. and Urman, B. (2009) High Dose Cabergoline in Management of Ovarian Hyperstimulation Syndrome. Fertility and Sterility, 92, 1168.e1-1168.e4.

[20] Seow, K.M., Lin, Y.H., Bai, C.H., Chen, H.J., Hsieh, B.C., Huang, L.W., Tzeng, C.R. and Hwang, J.L. (2013) Clinical Outcome According to Timing of Cabergoline Initiation for Prevention of OHSS: A Randomized Controlled Trial. Reproductive BioMedicine Online, 26, 562-568. http://dx.doi.org/10.1016/j.rbmo.2013.03.002

[21] Novella-Maestre, E., Carda, C., Noguera, I., Ruiz-Saurí, A., García-Velasco, J.A., Simón, C. and Pellicer, A. (2009) 
Dopamine Agonist Administration Causes a Reduction in Endometrial Implants through Modulation of Angiogenesis in Experimentally Induced Endometriosis. Human Reproduction, 24, 1025-1035.

http://dx.doi.org/10.1093/humrep/den499

[22] Zanettini, R., Antonini, A., Gatto, G., Gentile, R., Tesei, S. and Pezzoli, G. (2007) Valvular Heart Disease and the Use of Dopamine Agonists for Parkinson's Disease. The New England Journal of Medicine, 356, 39-46. http://dx.doi.org/10.1056/NEJMoa054830

[23] Herring, N., Szmigielski, C., Becher, H., Karavitaki, N. and Wass, J.A. (2009) Valvular Heart Disease and the Use of Cabergoline for the Treatment of Prolactinoma. Clinical Endocrinology, 70, 104-108.

http://dx.doi.org/10.1111/j.1365-2265.2008.03458.x 